\title{
ARTIGO
}

\section{Inclusão da pessoa com deficiência: análise de empregabilidade}

\author{
Inclusion of people with disabilities: employability analysis
}

\begin{abstract}
Anna Beatriz de Alencar Reis, Esp.
Advogada. Especialista em Direito do Trabalho pela Universidade de São Paulo (FDUSP, 2019). E-mail: annabalencar@gmail.com

Daiane Brasil Pereira Silva, Esp.

Advogada. Pós-graduanda em Direito e Processo Previdenciário pela Academia Jurídica. Especialista em Direito do Trabalho pela Universidade de São Paulo (FDUSP, 2019). Formada pela Universidade São Judas Tadeu (2017). E-mail: daianebrasilp@gmail.com
\end{abstract}

\section{Marcela Vasconcellos Santos de Andrade, Esp.}

Analista Judiciário - Área Judiciária do TRT da 2a Região. Especialista em Direito do Trabalho pela Universidade de São Paulo (FDUSP, 2019). Formada pela Universidade Presbiteriana Mackenzie (julho/2010). Email: marcelavsandrade@hotmail.com

Monique Dominicheli do Nascimento Basso, Esp.

Advogada. Mestranda em Direito do Trabalho na Universidade de São Paulo (FDUSP, 2020). Pesquisadora voluntária do Núcleo de Pesquisa "O trabalho além do direito do trabalho: dimensões da clandestinidade jurídico-laboral" (NTADT). Especialista em Direito do Trabalho pela Universidade de São Paulo (FDUSP, 2019). Pósgraduada em Direito e Processo do Trabalho na PUC-SP (2009). Formada pela Faculdade de Direito de São Bernardo do Campo (2007). E-mail: dominicheli@hotmail.com

RESUMO: O presente artigo trata sobre a inclusão da pessoa com deficiência no mercado de trabalho abordando aspectos histórico, legislativo e social, principalmente em relação às discriminações enfrentadas por esses trabalhadores. São importantes os instrumentos normativos internacionais que regem os direitos das pessoas com deficiência, pois reconhecem seu caráter de direitos humanos e não só proíbem que sejam discriminados como asseguram o exercício de todos os direitos de forma plena, equitativa e acessível. O artigo aborda o conceito do que é pessoa com deficiência demonstrando

Laborare. Ano IV, Número 6, Jan-Jun/2021, pp. 226-245. ISSN 2595-847X. https://revistalaborare.org/ DOI: https://doi.org/10.33637/2595-847x.2021-79 
sua constante evolução e o avanço do paradigma da deficiência que não se limita à pessoa, mas sim de sua interação com as barreiras impostas pelo ambiente e sociedade. A Organização das Nações Unidas (ONU) destaca que há ao menos 1 bilhão de pessoas com deficiência no mundo e que a taxa mundial de emprego de pessoas com deficiência é de $36 \%$ enquanto a de pessoas sem deficiência é de $60 \%$ e neste sentido, o artigo também traz dados de outras pesquisas oficiais. Quando se verifica que o primeiro relatório mundial sobre pessoas com deficiência no âmbito das Nações Unidas foi realizado somente em 2018, percebe-se quão importante é tratar do tema, não só por meio de estudos teóricos, mas principalmente buscar a implementação de ações que de fato incluam as pessoas com deficiência na sociedade, sendo o direito ao trabalho importante instrumento de emancipação social e econômica com o fim de que possam exercer seus direitos com sua dignidade.

Palavras-chave: acessibilidade, direito do trabalho, não discriminação.

ABSTRACT: This article deals with the inclusion of people with disabilities in the labor market, addressing historical, legislative and social aspects, mainly in relation to the discrimination faced by these workers. International normative instruments governing the rights of persons with disabilities are important, as they recognize their character as human rights and not only prohibit them from being discriminated against but also ensure the exercise of all rights in a full, equitable and accessible manner. The article addresses the concept of what a person with a disability is, demonstrating its constant evolution and the advancement of the disability paradigm that is not limited to the person, but rather its interaction with the barriers imposed by the environment and society. The United Nations (UN) points out that there are at least 1 billion people with disabilities in the world and that the global employment rate of people with disabilities is $36 \%$ while that of people without disabilities is $60 \%$ and in this sense, the article also contains data from other official surveys. When it appears that the first world report on people with disabilities at the United Nations was carried out only in 2018, it is clear how important it is to address the issue, not only through theoretical studies, but mainly to seek the implementation of actions that fact include people with disabilities in society, the right to work being an important instrument of social and economic emancipation so that they can exercise their rights with their dignity.

Keywords: accessibility, labor law, non-discrimination.

Laborare. Ano IV, Número 6, Jan-Jun/2021, pp. 226-245. ISSN 2595-847X. https://revistalaborare.org/ DOl: https://doi.org/10.33637/2595-847x.2021-79 


\section{INTRODUÇÃO}

O presente trabalho tem como objetivo investigar o panorama da empregabilidade das pessoas com deficiência no Brasil. Pretende-se, como objetivo específico, evidenciar as características do mercado de trabalho no que tange os tipos de deficiência, o tipo de trabalho e as vagas de emprego. Para tanto, apresenta-se como referencial teórico a terminologia e o conceito da pessoa com deficiência em sua perspectiva histórica relacionada ao princípio da dignidade da pessoa humana, do valor social do trabalho e da livre iniciativa, bem como de forma breve, a evolução da legislação sobre a sua inserção no mercado de trabalho.

A discriminação das pessoas com deficiência é um ato recorrente evidenciado no processo de inclusão no trabalho, tanto de forma direta quanto indireta, nesta última quando os efeitos das ações também afetam a inclusão, conforme os termos da Convenção 111 da Organização Internacional do Trabalho (OIT), ratificada e promulgada pelo Decreto n. ${ }^{\circ} 62.150 / 1968$.

Neste sentido, discutir acerca do panorama do mercado de trabalho possibilita refletir sobre a real inclusão das pessoas com deficiência e processos discriminatórios, assim como se há, efetivamente, avanços da aplicabilidade das legislações como forma de se garantir a igualdade de oportunidades.

O relatório da Organização Mundial da Saúde (OMS, 2011, p. 237) demonstra que pessoas com deficiência têm menores taxas de emprego em $52,8 \%$ para homens com deficiência $(64,9 \%$ para homens sem deficiência) e 19,6\% para mulheres com deficiência (29,9\% para mulheres sem deficiência).

Vale ressaltar que o ordenamento jurídico atual se concebe em Estado Democrático de Direito e elege a dignidade da pessoa humana como um de seus fundamentos, como consta no artigo $1^{\circ}$, III da Constituição, afastando o tratamento discriminatório e o preconceito em todas as possíveis formas, além de ressaltar o bem-estar social com medidas de políticas afirmativas de inclusão.

Para tanto, com o intuito de se investigar a participação das pessoas com deficiência no mercado de trabalho, inicialmente foram verificados dados do último censo do Instituto Brasileiro de Geografia e Estatística (IBGE) de 2010, da Relação Anual de Informações Sociais (RAIS) dos anos de 2011 e 2018, dados do Sistema Integrado de Vagas e Currículos para Pessoas com Deficiências (SIVC) e do Relatório Mundial sobre pessoas com deficiência da Organização das Nações Unidas (ONU) de 2018, como forma de

Laborare. Ano IV, Número 6, Jan-Jun/2021, pp. 226-245. ISSN 2595-847X. https://revistalaborare.org/ DOI: https://doi.org/10.33637/2595-847x.2021-79 
visualizar tipos de deficiências, gênero, quantidade de vínculos ativos e vagas de trabalho, permitindo tecer mais articulações sobre o impacto na empregabilidade.

\section{PESSOAS COM DEFICIÊNCIA}

Inicialmente, cumpre contextualizar a história sobre as pessoas com deficiência na sociedade, a fim de se demonstrar como essa estrutura ainda prejudica a plena aplicação da legislação a respeito do tema.

No período da Antiguidade, era comum na região de Esparta, sacrificar as crianças que nasciam com qualquer tipo de deficiência. Já os hebreus consideravam como um castigo divino ou um mau sinal. De modo semelhante, a segregação e a discriminação persistiram na Idade Média, pois se acreditava que tais pessoas tinham certas ligações com divindades malignas ou bruxarias. Em Roma, a lei das XII Tábuas permitia que os patriarcas matassem seus filhos com deficiência (SANTOS, 2019, p. 107). Durante esse período, utilizavam-se termos pejorativos tais como ceguinho, aleijadinho, ou outras nomenclaturas que realçavam as características físicas ou psíquicas das pessoas consideradas "anormais".

Com o início da doutrina cristã, deu-se lugar a um segundo momento do tratamento às pessoas com deficiência, com ênfase na caridade e assistencialismo. Esse período coincide com a criação no Brasil durante o Império, de instituições de assistência como o Imperial Instituto dos Meninos Cegos, em 1854 (atual Instituto Benjamin Constant) e o Instituto dos Surdos Mudos, em 1857, atual Instituto Nacional da Educação dos Surdos. Não obstante, foi a partir do século XX que ganhou ênfase e espaço o tratamento social, notadamente, em âmbito regional com a Convenção Interamericana para a Eliminação de Todas as Formas de Discriminação contra as Pessoas Portadoras de Deficiência de 2001 e após, no âmbito global com a Convenção de Nova Iorque sobre as Pessoas com Deficiência, de 2006. A Organização Internacional do Trabalho (OIT) aprovou em 1983 a Convenção 159 sobre reabilitação profissional e emprego de pessoas com deficiência.

Com a alteração de paradigma, passa-se a reconhecer o aspecto relacional da deficiência, não mais atrelada unicamente à característica do indivíduo, mas entendida como a relação que se estabelece com o ambiente no qual se encontra. Deste modo, a deficiência passa a ser definida com base não só no critério biomédico, mas também considera as barreiras sociais e ambientais enfrentadas.

Laborare. Ano IV, Número 6, Jan-Jun/2021, pp. 226-245. ISSN 2595-847X. https://revistalaborare.org/ DOl: https://doi.org/10.33637/2595-847x.2021-79 
Nesse influxo, a terminologia adotada também foi alvo de mudança, passando a ser pessoa com deficiência, em substituição dos termos "aleijado", "mutilado", "inválidos" presentes no Decreto n. ${ }^{\circ} 3.010 / 1938$, bem como "defeituosos", utilizado por exemplo na criação da Associação de Assistência à Criança Defeituosa (AACD) na década de 50, "pessoas com necessidades especiais" oriunda da Carta de Salamanca, "pessoas deficientes" utilizado pela Convenção 159 da OIT, "pessoa portadora de deficiência" utilizado a partir de 1985 com a Lei n. ${ }^{0} 7.405 / 1985$ e na Constituição de 1988. Apresenta-se, portanto, um conceito de interação, tendo em vista que a pessoa não é a deficiência e não porta a deficiência, mas apenas a possui em determinados contextos.

Salienta-se que essa nova concepção trazida pela Convenção Internacional dos Direitos das Pessoas com Deficiência, reforçada pelo Protocolo facultativo e o Tratado de Marraqueche, todos aprovados com status constitucional, foi também positivada na Lei n. ${ }^{\circ}$ 13.146/2015, que inaugura, no Brasil, o Estatuto das Pessoas com Deficiência. Assim, conforme o artigo $2^{\mathrm{a}}$, adota-se um conceito relacional e social da pessoa com deficiência.

Com o objetivo de estabelecer a plena cidadania às pessoas com deficiência, foram revogados diversos artigos do Código Civil, os quais previam tais pessoas como incapazes. Além disso, a Convenção e o Estatuto buscam aplicar de forma significativa a inclusão social, o que se verifica na previsão de obtenção do consentimento, no maior grau possível, da pessoa com deficiência no caso de curatela (artigo 12, §1 $1^{\circ}$, Lei n. ${ }^{\circ} 13.145 / 2015$ ).

Logo, o que se busca são a inclusão e participação efetivas, adaptação e medidas de proteção pela sociedade como a igualdade de acesso, oportunidades, qualidade de vida e vida digna para as pessoas com deficiência, o que, inclusive, está encampado pela Agenda 2030 da Organização das Nações Unidas (ONU) na área de emprego pleno, produtivo e de igual remuneração.

Deste modo, conforme se verá a seguir, a despeito da segregação e o assistencialismo estarem ultrapassados e eivados de preconceito, estereótipos e estigmas, ainda persiste uma visão restritiva de direitos às pessoas com deficiência, retirando-lhes parcelas de cidadania, especialmente, no mercado de trabalho.

\section{VALOR SOCIAL DO TRABALHO E LIVRE INICIATIVA À LUZ DA PROTEÇÃO DA DIGNIDADE DA PESSOA HUMANA}

Laborare. Ano IV, Número 6, Jan-Jun/2021, pp. 226-245. ISSN 2595-847X. https://revistalaborare.org/ DOI: https://doi.org/10.33637/2595-847x.2021-79 
Sabemos que o Estado Democrático de Direito se funda em um tripé conceitual: centralidade da pessoa humana (e sua dignidade), sociedade política e sociedade civil, ambas, conforme aduzem Delgado e Delgado (2017), necessariamente democráticas e inclusivas. Deste modo, não se admite no ordenamento jurídico brasileiro qualquer forma de discriminação, sendo todos iguais perante a lei. Nesse sentido, a Constituição estabeleceu a promoção do bem de todos, sem preconceitos de origem, raça, sexo, cor, idade e quaisquer outras formas de discriminação (artigo $3^{\circ}$, inciso IV); promovendo a liberdade e a igualdade entre todos (artigo $5^{\circ}$, caput); determinando a punição, por meio de lei, de qualquer discriminação atentatória dos direitos e liberdades fundamentais (artigo $5^{\circ}$, inciso XLI); proibindo qualquer discriminação no tocante a salário e critérios de admissão do trabalhador com deficiência (artigo $7^{\circ}$, inciso XXXI) e a criação pelo Estado de programas de prevenção, atendimento especializado e integração para as pessoas com deficiência. (artigo $227, \S 1^{\circ}$, inciso II).

Entretanto, para a eficácia desses institutos, a sociedade deve torná-los tangíveis às pessoas com deficiência, respeitando as diferenças e promovendo a inclusão. Nesse sentido, conforme aponta Lemos (2015), a inclusão social das pessoas com deficiência é essencial à sua dignidade e ao alcance da igualdade com os demais cidadãos, assegurando-lhes independência financeira e realização pessoal. Deste modo, o princípio da dignidade da pessoa humana se aplica de maneira soberana, considerando sua vulnerabilidade social, revelando-se essenciais ações afirmativas e políticas públicas que contribuam para sua inclusão social (DE LUCA e RENZETTI FILHO, 2018).

O reconhecimento da dignidade da pessoa humana como elemento central da Constituição direciona a ação do Estado para a valorização do ser humano, visto como um fim em si mesmo e não como um mero instrumento para resultados alheios, assistindo-lhe, assim, o direito à condição de vida cada vez melhor. Nesse contexto, é importante promover oportunidades às pessoas com deficiência em um sentido amplo, inclusive, com acessibilidade arquitetônica, física, intelectual, educacional, conferindo-lhe efetiva participação na sociedade.

Não é suficiente afirmar que a igualdade na lei é capaz de tutelar os direitos das pessoas com deficiência. Para Américo Plá Rodriguez (2000, p. 166), reconhecer a igualdade formal não impede que o Estado crie leis aplicáveis a um grupo específico de pessoas, sendo necessária, portanto, a análise da razoabilidade da discriminação. Por conseguinte, essas ações adotadas aos trabalhadores com deficiência assumem o

Laborare. Ano IV, Número 6, Jan-Jun/2021, pp. 226-245. ISSN 2595-847X. https://revistalaborare.org/ DOl: https://doi.org/10.33637/2595-847x.2021-79 
dever de concretização da ordem em equilíbrio social, caracterizando uma discriminação positiva.

O trabalhador é agente de transformação da economia e, ao alienar sua força de trabalho, aliena parte de sua existência (MARQUES, 2016). Deste modo, conforme aponta Delgado (2017a) o trabalho constitui, portanto, relevante instrumento de afirmação da democracia na vida social.

O artigo 193 da Constituição estabelece que o primado do trabalho, bem-estar e justiça social são bases da ordem social. Consoante destacam Delgado e Delgado (2017), a livre iniciativa se enquadra como valor social (artigo $1^{\circ}$, IV, da Constituição), devendo, assim, amoldar-se aos princípios constitucionais humanísticos. Referidos autores discorrem acerca da principiologia da Constituição, afirmando que os princípios gerais da atividade econômica presentes no Capítulo I do Título VII, consolidam a valorização do trabalho e da livre iniciativa com o objetivo de assegurar a todos, existência digna conforme os ditames da justiça social.

É necessário compreender que a limitação decorrente da deficiência não significa a incapacidade para exercer suas funções, uma vez que é completamente possível realizar sua adaptação às atividades. A inclusão das pessoas com deficiência no mercado de trabalho é dirigente do seu reconhecimento social e profissional, reduzindo o estigma de sua incapacidade e promovendo seu bem-estar (PASTORE, 2000, apud MACIEL, 2011). Por outro lado, a empresa também possui relevante papel na formação dos trabalhadores com deficiência, sobretudo em face do princípio constitucional da função social da propriedade e da responsabilização social.

Desta maneira, em consonância com os postulados consagrados na Constituição, que veda o tratamento discriminatório, a inclusão social das pessoas com deficiência constitui dever não só do Estado como de toda a sociedade, inclusive, dos empregadores. Contudo, não basta que as legislações consagrem os direitos das pessoas com deficiência, se não há medidas sociais para efetivá-los. Só haverá inclusão social, garantindo-se o trabalho, porquanto este se revela não só meio de subsistência mas fator da realização da dignidade humana.

\section{INCLUSÃO DA PESSOA COM DEFICIÊNCIA NO MERCADO DE TRABALHO}

A dificuldade de inclusão das pessoas com deficiência no mercado de trabalho tem como principal nuance a questão do preconceito sobre sua possível incapacidade.

Laborare. Ano IV, Número 6, Jan-Jun/2021, pp. 226-245. ISSN 2595-847X. https://revistalaborare.org/ DOl: https://doi.org/10.33637/2595-847x.2021-79 
Pressupõe-se que tais pessoas não têm aptidão para realizar atividades mais complexas ou mesmo para contribuir com o aumento de produtividade da empresa e, por consequência, o objetivo de lucro empresarial. Essa visão arcaica deságua na discriminação negativa, conduta pela qual se nega à pessoa, em face de critério injustamente desqualificante, tratamento compatível com o padrão jurídico assentado para a situação concreta por ela vivenciada (DELGADO, 2017b), o que é rechaçado em âmbito nacional e internacional. Ocorre que, como a conduta meramente repressiva da discriminação não é suficiente para inibi-la, mostra-se relevante o conceito de discriminação positiva, o qual tem por escopo conferir tratamento desigual a determinados grupos em situação de desvantagem, favorecendo-os com alguma medida afirmativa.

É importante destacar que não só a ideia de incapacidade gera discriminações. Outros fatores contribuem para essa exclusão tais como educação, pobreza, sobreposições de tipos de deficiência ou ainda quando esses fatores se interseccionam, conforme apontado no relatório da ONU (2019, p.152). A autora Becker (2019, p.42) aponta, com base no Relatório da Pesquisa Nacional de Saúde de 2013, que o estado de saúde das pessoas com deficiência já fez com que fossem oferecidos salários mais baixos. Em relação ao acesso à educação, o relatório das Nações Unidas (UN, 2018, p.76) aponta que em um grupo de população entre 15 e 29 anos de idade que tenha frequentado a escola alguma vez, considerando 41 países em desenvolvimento, $87 \%$ foi de jovens sem deficiência, e $75 \%$ de jovens com deficiência, fator que pode afetar as oportunidades de emprego.

O retrospecto histórico já abordado demonstra que há diversas discriminações enfrentadas pelas pessoas com deficiência. O próprio artigo 433 da Consolidação das Leis do Trabalho (CLT) permitia que o aprendiz com deficiência tivesse seu contrato de trabalho rescindido antecipadamente por desempenho insuficiente ou inadaptação, sendo revogado somente em 2015 com o Estatuto da Pessoa com Deficiência.

Desta forma, medidas como a reserva legal para pessoas com deficiência e reabilitadas é uma importante política pública que tem por propósito contribuir para a empregabilidade desse grupo vulnerável, encontrando amparo no artigo 37, VIII, da Constituição, para o setor público e no artigo 93 da Lei n. ${ }^{\circ} 8.213 / 1991$, para o setor privado.

Em linhas gerais, a reserva legal das vagas oferecidas às pessoas com deficiência nos concursos públicos está fixada entre $5 \%$ e $20 \%$. A Lei n. ${ }^{\circ} 8.112 / 1990$, conhecida como o estatuto do servidor público, instituiu o limite da reserva legal no percentual de 20\%. Posteriormente, o Decreto n. ${ }^{\circ} 3.298 / 1999$ disciplinou o mínimo legal de 5\%,

Laborare. Ano IV, Número 6, Jan-Jun/2021, pp. 226-245. ISSN 2595-847X. https://revistalaborare.org/ DOl: https://doi.org/10.33637/2595-847x.2021-79 
tudo nos termos do artigo 37, VIII, da Constituição. As disposições relativas à reserva de vagas para pessoas com deficiência estabelecidas pelo Decreto n. ${ }^{\circ} 3.298 / 1999$ foram substituídas por aquelas contidas no Decreto n. ${ }^{\circ}$ 9.508/2018, mantendo-se o percentual mínimo de $5 \%$, consoante artigo $1^{\circ}, \S 1^{\circ}$. Deste modo, compete à administração pública na realização dos editais e das provas dos concursos, informar o número de vagas existentes e as reservadas às pessoas com deficiência, atribuições e tarefas dos cargos e a adaptação das provas.

Já no setor privado, a regra geral é determinada pela Lei n. ${ }^{0} 7.853 / 1989$ que dispõe sobre apoio e integração social das pessoas com deficiência e previu em seu artigo $2^{\circ}$, III, "d" criação de lei específica, a fim de disciplinar a reserva de vagas, sendo regulamentada pelos decretos números 3.048/1999 e 3.298/1999 e pela Lei n. ${ }^{\circ}$ $8.213 / 1991$ em seu artigo 93. A reserva de vagas considerou o critério de número de empregados por empresa, com no mínimo de $2 \%$ para as que tenham de 100 a 200 empregados e máximo de $5 \%$ para as que tenham acima de mil empregados.

Ressalta-se que este percentual também é aplicado as instituições sem fins lucrativos, pois referida regra destina-se a todas as pessoas jurídicas de direito privado, inclusive às as sociedades empresariais, associações, sociedades e fundações que admitem trabalhadores, nos termos do artigo $2^{\circ}, \S 1$ da CLT.

As concepções de Fávero (2004) nos permite apontar que há dois modelos acerca do tratamento às pessoas com deficiência, sendo: a) sociedade integrativa, na qual se vislumbra a necessidade de mudança da própria pessoa com deficiência, isto é, buscase a "normalização" de um ser humano visto como patológico, para que este se adeque à sociedade, retirando do Estado e da sociedade a obrigação de promover um ambiente plenamente acessível; b) sociedade inclusiva, buscando a inserção total e incondicional das pessoas com deficiência, sem a pretensão de disfarçar as limitações existentes. A última posição valoriza a individualidade a partir da certeza de que todas as pessoas são diferentes, direcionando o acolhimento de todos, focando na necessidade de remoção de barreiras, de instituição de políticas públicas e demais ações que possibilitem a convivência de todos os seres humanos, construindo uma sociedade inclusiva e avançando em comparação à ideia que observa tão somente as igualdades de condições.

No mais, verifica-se que o artigo $1^{\circ}$ da Lei $n .^{\circ} 12.146 / 2015$ optou, expressamente, pelo modelo inclusivo, ao dispor: "visando à sua inclusão social e cidadania"; bem como, as demais disposições legais, em especial, a Seção III (Da Inclusão da Pessoa com Deficiência no Trabalho), do Capítulo VI (Do Direito ao Trabalho). Desta

Laborare. Ano IV, Número 6, Jan-Jun/2021, pp. 226-245. ISSN 2595-847X. https://revistalaborare.org/ DOl: https://doi.org/10.33637/2595-847x.2021-79 
forma, os dispositivos do ordenamento jurídico devem ser interpretados à luz da doutrina da inclusão em todas as áreas, até mesmo no mercado de trabalho.

Assim, tem-se por certo que o simples cumprimento do percentual obrigatório da cota não é suficiente para concretizar o conceito de inclusão social, mas se revela como um primeiro passo na diretriz da plena igualdade, consubstanciada na Constituição e nos diplomas internacionais específicos. Não obstante, há inúmeros dilemas enfrentados pelo Poder Judiciário na aplicação da Lei n. ${ }^{\circ} 8.213 / 1991$.

Questiona-se, por exemplo, a possibilidade de excluir da base de cálculo determinados cargos que, em tese, não permitiriam o trabalho da pessoa com deficiência, por meio de acordo ou convenção coletiva. O Tribunal Superior do Trabalho (TST), em 2017, por meio da Seção de Dissídios Coletivos, em ação anulatória, validou a restrição feita por norma coletiva da categoria de segurança privada por entender razoável diante da realidade do setor em contraposição às alegações do Ministério Público do Trabalho (MPT), que entendia que não poderia haver "concepção prévia da incapacidade de qualquer deficiente" (BRASIL, 2017). Entretanto, em decisão de 2020 o TST anulou cláusula que limitava contratação de pessoas com deficiência em empresas aéreas, sob argumento de que a as partes não poderiam pactuar sobre interesses difusos (no caso, pessoas com deficiência) e que o artigo 93 da Lei n. ${ }^{\circ} 8.213 / 1991$ não prevê qualquer exceção de cargos ou atividades para o cômputo do cálculo. (BRASIL, 2020).

Neste sentido, o Supremo Tribunal Federal (STF), na decisão da Ação Direta de Inconstitucionalidade (ADI) n. ${ }^{\circ}$ 5.760, entendeu pela impossibilidade de exclusão dos trabalhadores marítimos embarcados dos cálculos para apuração das cotas, considerando não haver vedação legal ou convencional ao trabalho de pessoas com deficiência nas embarcações, muito embora "a legislação que disciplina o trabalho marítimo exija a submissão do trabalhador a uma avaliação prévia das condições físicas, médicas e psicológicas". De fato, a limitação de acesso em vaga específica, eventualmente, poderá ocorrer a depender da limitação pessoal e natureza do posto de trabalho. Contudo, não há falar em incapacitação geral do trabalhador com deficiência para o desempenho de atividades laborais em embarcações. $\mathrm{O}$ ministro relator explicitou que a exclusão dos embarcados do cômputo de vagas reservadas às pessoas com deficiência ofende a isonomia, pois ao reduzir os postos de trabalho ofertados aos trabalhadores marítimos com deficiência os deixa em desvantagem em relação àqueles com deficiência que trabalham em outros ramos (BRASIL, 2019).

Laborare. Ano IV, Número 6, Jan-Jun/2021, pp. 226-245. ISSN 2595-847X. https://revistalaborare.org/ DOl: https://doi.org/10.33637/2595-847x.2021-79 
Outras questões enfrentadas para uma concretização efetiva do trabalho inclusivo são a inexistência de um plano adequado para qualificação dos candidatos com deficiência e a dificuldade de, mesmo com fiscalização, se alcançar o cumprimento da reserva legal. Isso porque, embora haja previsão de multa administrativa em valor significativo (R \$2.656,61 por trabalhador não contratado, podendo chegar ao teto de R \$ 265.659,51) aplicada pela Inspeção do Trabalho do Ministério da Economia, conforme sua Portaria número 477 de 12 de janeiro de 2021, a média do cumprimento da cota para pessoas com deficiência é de $50,62 \%$, sendo $11,21 \%$ na administração pública, $45,65 \%$ em empresas públicas e sociedade de economia mista e $52 \%$ nos empregadores privados ${ }^{1}$.

Assim, tais problemas desestimulam os empregadores a contribuírem para a inclusão social, bem como de observar a função social da propriedade (artigo 170, III, Constituição) e do contrato (artigo 421, Código Civil), sendo certo que o Estatuto da Pessoa com Deficiência dispõe expressamente no artigo $36, \S 5^{\circ}$, acerca da responsabilidade dos empregadores na habilitação de seus próprios empregados, estabelecendo-se uma articulação entre o Estado e setor privado.

Ressalte-se que eximir o empregador de responsabilidade contraria Convenções Internacionais da OIT ratificadas pelo Brasil, em especial a de número 111, e a Convenção Interamericana para a Eliminação de Todas as Formas de Discriminação contra as Pessoas Portadoras de Deficiência. Tais diplomas possuem como objetivo promulgar leis e encorajar os programas de educação, alentar as autoridades governamentais e entidades privadas para eliminar progressivamente a discriminação e promover a integração na prestação ou fornecimento de bens, com o objetivo maior de proporcionar a plena inclusão da pessoa com deficiência à sociedade.

Contudo, algumas decisões do TST atenuam a responsabilidade das empresas pelo insucesso do preenchimento da cota, desde que provados os esforços para seu cumprimento. Nesse sentido cita-se o julgamento ocorrido em ação civil púbica na SBDI-I do TST, tendo como relator o Ministro João Batista Brito Pereira, que entendeu que a empresa diligenciou pela busca de candidatos, não cabendo dano moral coletivo ou multa neste sentido, mas que "não a exonera da obrigação de promover a admissão de pessoas portadoras de deficiência ou reabilitados, nos termos da lei." (BRASIL, 2016a).

Entretanto, em que pese as possíveis dificuldades enfrentadas pelas empresas, é preciso sempre buscar alternativas para o preenchimento das vagas, inclusive oferecendo

1 Dados disponíveis no endereço eletrônico do Portal da Inspeção do Trabalho, pelo painel de Informações estatísticas da Inspeção do Trabalho: https://sit.trabalho.gov.br/radar/. Acesso em 30 jan. 2021.

Laborare. Ano IV, Número 6, Jan-Jun/2021, pp. 226-245. ISSN 2595-847X. https://revistalaborare.org/ DOl: https://doi.org/10.33637/2595-847x.2021-79 
adaptações razoáveis ao exercício da função ou meio de transporte que facilite o acesso dos trabalhadores com deficiência aos postos de trabalho, em busca da efetiva inclusão. Neste sentido, ao almejar a inclusão, o STF no julgamento da ADI n. ${ }^{\circ} 5.357$ posicionou-se pela inclusão de alunos com deficiência, entendendo que as escolas particulares devem prover as medidas de adaptação necessárias, sem que haja diferenças nos valores das mensalidades, anuidades ou matrículas em virtude de qualquer deficiência. (BRASIL, 2016b). Assim, a ratio decidendi da ADI n. ${ }^{\circ} 5.357$ e da ADI n. ${ }^{\circ} 5.760$ devem servir de parâmetro para outras decisões que tratem sobre direitos da pessoa com deficiência à luz da aplicação da Convenção de Nova Iorque de 2006.

De outro ângulo, é importante ressaltar que mesmo com o preenchimento da reserva de vagas, não é possível afirmar que há efetiva inclusão das pessoas com deficiência, pois, comumente, as vagas são ofertadas com o único intuito de preencher a cota, não se atentando às aptidões dos candidatos, nem à possibilidade de crescimento profissional. Assim, as consequências dessas posturas podem resultar em discriminações tais como isolamento dos empregados, dispensa do seu comparecimento ao trabalho, ausências de plano de carreira e/ou promoções e falta de adaptações no ambiente de trabalho que podem ser coibidas pela fiscalização da Auditoria Fiscal do Trabalho, pelo Ministério Público do Trabalho e inclusive pelos sindicatos.

Como visto, cabe aos empregadores remover todas as barreiras que impeçam ou prejudiquem a participação da pessoa com deficiência no trabalho, inclusive, as barreiras atitudinais. Nesse último caso, é aconselhável que os demais empregados também sejam orientados a auxiliar e incluir as pessoas com deficiência. Assim, vislumbra-se que os empregadores devem cumprir a função social que thes corresponde constitucionalmente e, através de atitudes inclusivas, possibilitar às pessoas com deficiência o acesso ao trabalho digno, de acordo com suas aptidões e preferências, eliminando toda e qualquer barreira existente.

\section{RESULTADOS E ANÁlises SOBRE O PANORAMA DE EMPREGABILIDADE}

No mundo há um bilhão de pessoas com deficiência, o equivalente a $15 \%$ da população global e cerca de $80 \%$ delas estão em idade econômica ativa (ONU, 2019). No Brasil, de acordo com o IBGE $(2010)^{2}, 6,7 \%$ da população têm algum tipo de deficiência. Levando-se em consideração os desafios enfrentados pelas pessoas com deficiência e a resistência encontrada para sua plena inclusão na sociedade, é crível

2 De acordo com a Nota Técnica 01/2018 do IBGE que revisou os dados de acordo com as recomendações propostas pelo Grupo de Washington sobre Estatísticas das Pessoas com Deficiência.

Laborare. Ano IV, Número 6, Jan-Jun/2021, pp. 226-245. ISSN 2595-847X. https://revistalaborare.org/ DOI: https://doi.org/10.33637/2595-847x.2021-79 
afirmar que ainda há muito a ser feito para lhes possibilitar um trabalho digno e livre de preconceitos.

Nesta seção se faz uma análise do último censo do IBGE, no ano de 2010, juntamente com a Relação Anual de Informações Sociais (RAIS) de 2011 e 2018 e do primeiro relatório mundial sobre pessoas com deficiência no âmbito das Nações Unidas (ONU) que foi realizado em 2018, com o objetivo de avaliar a situação das pessoas com deficiência no mercado de trabalho no Brasil.

A RAIS permite verificar as condições socioeconômicas solicitadas pelo Ministério da Economia aos empregadores, instituído pelo Decreto n. ${ }^{\circ}$ 76.900/1975. Quanto ao relatório da ONU sobre pessoas com deficiência, é importante destacar a meta de crescimento de emprego pleno, produtivo e de trabalho decente.

Percebe-se que ao longo dos anos houve um aumento de registros de vínculos empregatícios de pessoas com deficiência ativos no Brasil. Em 2011 foram constatados 325,3 mil vínculos de empregos de pessoas com deficiência, um total de $0,70 \%$ da totalidade dos vínculos empregatícios, ao mesmo tempo em que havia 46,311 milhões de vínculo ativos. A quantidade de vínculos formais para pessoas com deficiência aumentou em relação ao ano de 2011 em 49,65\% resultando em um número de 486,75 mil em 2018. Este aumento pode ter ocorrido em razão de alguns avanços, a serem pontuados: a) aprovação com status constitucional da Convenção sobre os Direitos da Pessoa com Deficiência; b) aprovação do Estatuto da Pessoa com Deficiência, que reafirmou a capacidade da pessoa com deficiência, bem como atribuiu responsabilidade aos empregadores pela sua habilitação no trabalho; c) alteração da legislação que não mais exclui o benefício de prestação continuada da pessoa com deficiência que ingressa no mercado de trabalho, mas apenas o suspende, assegurando-lhe sua reativação se houver a perda do emprego; d) implementação da lei de cotas; e) possíveis ações afirmativas e f) fiscalização para o efetivo cumprimento da legislação.

O relatório da ONU $(2019$, p.108) aponta que pessoas com deficiência, em especial mulheres, têm menor taxa de emprego do que homens com deficiência. Dado esse perceptível ao se analisar a quantidade de vínculos de emprego para pessoa com deficiência no Brasil, pois, em 2011, 213.847 mil vínculos de pessoas com deficiência eram ocupados pelo gênero masculino $(65,74 \%)$ e 111.444 mil $(34,26 \%)$ pelo gênero feminino. Ponto que esbarra no estigma do papel da mulher na sociedade, que, conforme apontam Mello e Nuernberg (2012), estaria neste caso em uma dupla desvantagem potencializando a discriminação da mulher com deficiência.

Laborare. Ano IV, Número 6, Jan-Jun/2021, pp. 226-245. ISSN 2595-847X. https://revistalaborare.org/ DOl: https://doi.org/10.33637/2595-847x.2021-79 
Em relação ao tipo de deficiência, a deficiência física abrangia um total de 230.345 mil vínculos de emprego em 2018, enquanto em 2011 eram de 174.207 mil; deficiência auditiva 87.992 mil em 2018 e 73.579 mil em 2011; deficiência visual

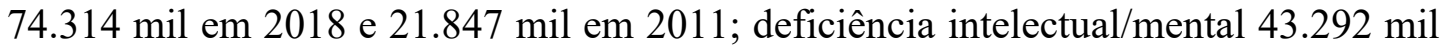
em 2018 e 18.819 mil em 2011; deficiência múltipla 9.162 mil em 2018 e 4.144 mil em 2011 e reabilitado de 41.651 mil em 2018 e 32.704 mil em 2011.

Percebe-se que o aumento de vínculos permanece nos mesmos tipos de deficiência, na medida em que a deficiência física ainda é o tipo de deficiência com a maior quantidade de vínculos, seguida da auditiva e visual, conforme se verifica no gráfico abaixo:

Gráfico 1: Vínculo por tipo de deficiência

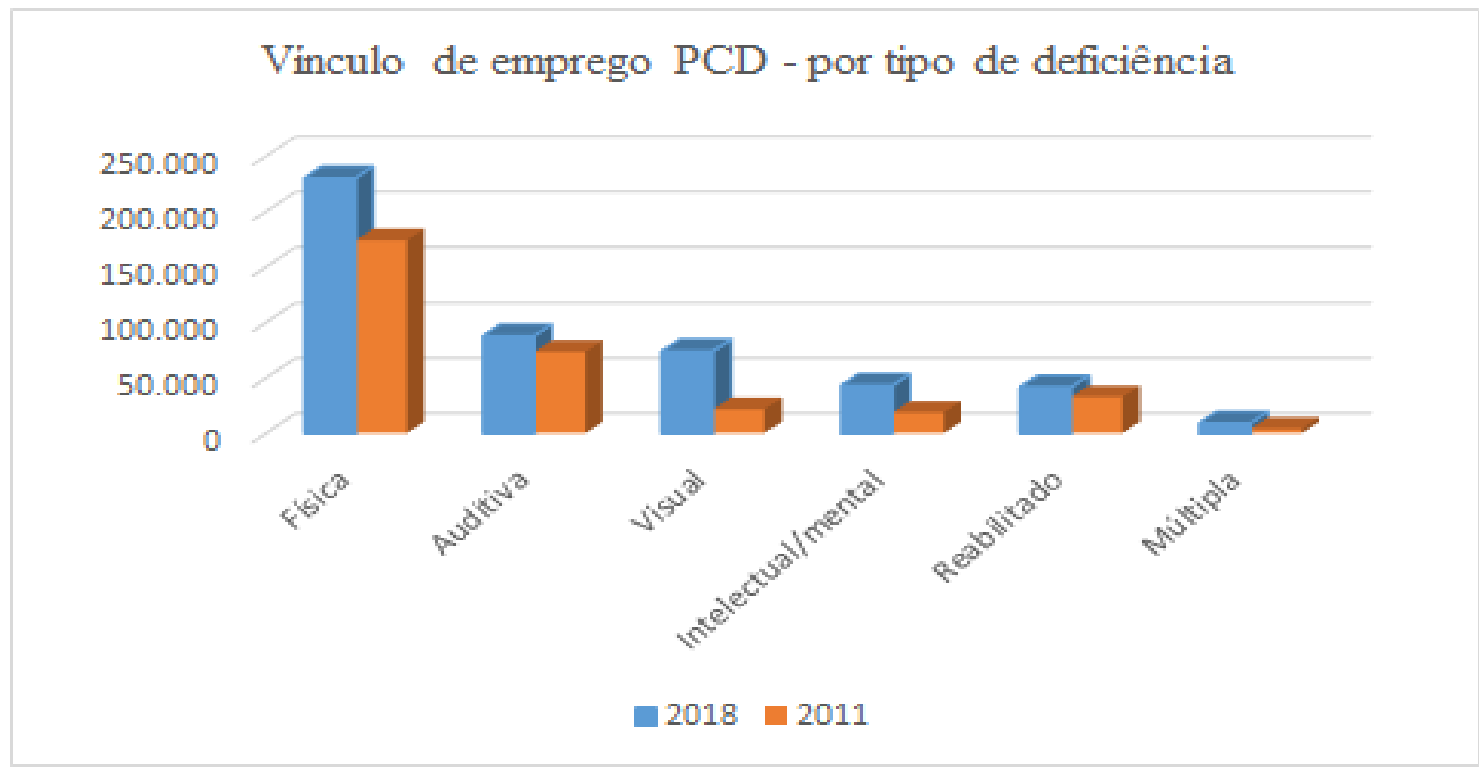

Fonte: Adaptado de RAIS 2011 e 2018

Nesse sentido, verifica-se que há preterições entre os tipos de deficiência para a inclusão no mercado de trabalho, uma vez que a cada tipo de deficiência sujeita-se a dificuldades específicas para a devida contratação. O relatório da ONU (2019, p.155) aponta que no Brasil pessoas com grau de deficiência mais severa tendem a enfrentar maiores obstáculos para conseguir uma vaga de emprego, o que demonstra que o profissional com esse grau de deficiência sofre distintos fatores de discriminação. 
Em relação às vagas de emprego, em 2009, o Sindicato das Empresas de Limpeza Urbana de São Paulo (SELUR) em cooperação com a Rede Saci ${ }^{3}$ e Coordenadoria Executiva de Cooperação Universitária e de Atividades Especiais da Universidade de São Paulo (CECAE-SP), que atua na comunicação e difusão de informação sobre a deficiência, visando a inclusão social, criaram um Sistema Integrado de Vagas e Currículos para Pessoas com Deficiências (SIVC).

O SIVC foi pensado para possibilitar e facilitar a colocação da pessoa com deficiência, ou as reabilitadas, no mercado de trabalho. As empresas podem oferecer as vagas de trabalho pelo site bem como é possível cadastrar currículos e procurar empregos. Os dados do portal SIVC de 11 de dezembro de 2020 demonstram que são 8.000 candidatos e 4.865 empresas, com a totalidade de 42.861 postos de trabalho para um número de 7.775 vagas/funções determinadas. Destas funções determinadas, 4.205 vagas não requerem experiência, 3.129 a exigem e 441 são vagas que não declararam esse requisito. (SELUR, 2020. p.1)

Quanto à escolaridade mínima requerida pelas vagas, 4.076 vagas exigem o ensino médio, 1.881 exigem o ensino fundamental, 1.080 o ensino superior, 19 para pósgraduação, 1 para o mestrado, nenhuma exigindo doutorado e 486 não requeridas. A quantidade de currículos cadastrados no sistema SIVC é de 8.000, sendo que 3.200 candidatos possuem ensino médio, 2.460 o ensino superior, 552 o ensino fundamental, 276 o ensino médio profissionalizante, 216 o ensino técnico, 365 pósgraduação, 26 mestrado, 5 doutorado e 2 pós-doutorado, o que demonstra que há mais candidatos qualificados do que as próprias vagas exigem. Quanto ao gênero, 4.106 candidatos são do sexo masculino, e 3.329 do sexo feminino.

Sobre o tipo de deficiência, 4.065 candidatos são pessoas com deficiência física, 1.505 deficiência auditiva, $421 \mathrm{com}$ deficiência intelectual $/$ mental, $73 \mathrm{com}$ deficiência múltipla, 988 com deficiência visual e 948 pessoas não declararam. Esses dados demonstram que, de fato, estão no topo das contratações pessoas com deficiência física, auditiva e visual. O Estado de São Paulo tem o maior número de cadastros tanto de vagas como de currículos, com 5.706 e 5.606, respectivamente. O Estado de Roraima não tem nenhuma vaga e 1 currículo cadastrado, Santa Catarina tem mais vagas do que currículos cadastrados (163 vagas e 72 currículos), sendo a região norte a que tem o menor índice de cadastro.

3 A Rede SACl é um projeto do Programa USP Legal, atua como facilitadora da comunicação e da difusão de informações sobre deficiência, visando a estimular a inclusão social e digital, a melhoria da qualidade de vida e o exercício da cidadania das pessoas com deficiência.

Laborare. Ano IV, Número 6, Jan-Jun/2021, pp. 226-245. ISSN 2595-847X. https://revistalaborare.org/ DOI: https://doi.org/10.33637/2595-847x.2021-79 
Atualmente ainda se verifica associação entre o tipo de deficiência e o ramo profissional, em razão do preconceito de que a pessoa com deficiência é incapaz de fazer determinadas atividades, além dos empregadores apenas buscarem o cumprimento das cotas previstas em lei. Segundo pesquisa realizada pelo i-Social com a empresa Catho e com a Associação Brasileira de Recursos Humanos (I.SOCIAL, 2015), com uma base de 1.459 profissionais de recursos humanos, $86 \%$ contratam pessoas com deficiência para cumprir a legislação de cotas, enquanto $9 \%$ contratam pelo currículo profissional, independentemente de cota ou tipo de deficiência. Nesse sentido, pode-se concluir que embora possa haver inserção da pessoa com deficiência no local de trabalho, não há a efetiva inclusão, respeitadas as aptidões, vocações ou interesses.

Neste aspecto, o estigma da incapacidade das pessoas com deficiência no sentido biomédico, não considera as barreiras sociais que impedem sua inclusão no trabalho. Ademais, as oportunidades devem ser amplas e substanciais, buscando-se melhorias de locomoção, acessibilidade intelectual, tecnológica e adaptação do meio ambiente de trabalho para que possam realizar suas funções, possibilitando qualificação e capacitação, afastando o simples objetivo do cumprimento de cotas.

Por fim, pensando no cenário atual da pandemia do novo coronavírus, foi aprovada a lei 14.020/2020 que proíbe a dispensa sem justa causa dos empregados com deficiência nesse período. Contudo, levantamento de dados feito pelo Departamento Intersindical de Estatísticas e Estudos Socioeconômicos, demonstra que no final de 2019 os vínculos formais das pessoas com deficiência era de 523,4 mil, o que representa $1,1 \%$ do total de ocupados formais (DIEESE, 2020, p.9). De janeiro a setembro de 2020 a taxa de desligamento sem justa causa das pessoas com deficiência foi de $35,8 \%$, superior ao da população em geral que é de $30,2 \%$ e o setor econômico de indústria de transformação é o responsável pelo maior número de vagas fechadas (25,7\%), seguido do comércio com 19,6\% (DIEESE, 2020, p.18).

A OIT ressaltou cinco pontos de atenção para a proteção de pessoas com deficiência no trabalho durante a pandemia: medidas de apoio para promover a igualdade; assegurar que a comunicação seja acessível e inclusiva; proporcionar proteção social adequada; assegurar o direito ao trabalho agora; mudar a narrativa para incluir pessoas com deficiência como cocriadoras de respostas à Covid-19 e não como vítimas. (OIT, 2020). Tais ações demonstram a função do trabalho como meio de inclusão social e elemento de existência humana.

\section{CONSIDERAÇÕES FINAIS}

Laborare. Ano IV, Número 6, Jan-Jun/2021, pp. 226-245. ISSN 2595-847X. https://revistalaborare.org/ DOl: https://doi.org/10.33637/2595-847x.2021-79 
O tema do presente artigo é um recorte sobre a empregabilidade das pessoas com deficiência. A questão histórica do relacionamento da sociedade com as pessoas com deficiência reflete o estigma e preconceito em relação à sua efetiva inclusão nas diversas estruturas de convivência, verificando-se ainda resquícios de segregação e discriminação presentes desde a antiguidade.

Contudo, com o desenvolvimento da teoria dos direitos humanos, abriu-se um leque para um modelo de tratamento social adequado ao princípio da dignidade humana, ao direito à liberdade, igualdade e não discriminação. Todavia, os preconceitos quanto às pessoas com deficiência e seus estereótipos atravessam seu cotidiano inclusive no direito ao trabalho.

A inclusão da pessoa com deficiência à vida comunitária depende de fatores como acesso à educação, direito à locomoção e à saúde, bem como na vida profissional, é necessária sua habilitação, reabilitação, capacitação e profissionalização não apenas pelo Estado, como pelos entes privados e toda a sociedade. Conforme análise realizada, os dados apresentados caracterizam um crescimento nas vagas e contratações para o trabalho, mas que decorrem pelo intuito do cumprimento obrigatório das cotas legais. Os dados também demonstram a interseccionalidade de outros fatores de discriminação que potencializam a dificuldade para a inclusão no trabalho, como gênero e tipos de deficiência e que por vezes os candidatos às vagas de emprego são mais qualificados do que a requerida pelos empregadores.

O trabalho humano constitui fonte de subsistência e existência, fator da dignidade da pessoa humana e elemento responsável pela realização profissional e pessoal. Devem ser eliminados não apenas os obstáculos arquitetônicos, como todas as formas de discriminação (artigo 227, §1 $1^{\circ}$, II parte final da Constituição), objetivando-se assim o real alcance do princípio constitucional da solidariedade (artigo $3^{\circ}$, inciso I).

Assim, embora seja inegável o reconhecimento dos direitos à propriedade privada, da livre iniciativa e da livre concorrência, tais institutos próprios do sistema capitalista, devem se amoldar aos demais princípios e normas constitucionais, tais como a centralidade da pessoa humana, função social da propriedade, valorização e primado do trabalho.

A legislação brasileira criou o sistema de cotas como medida afirmativa para inclusão das pessoas com deficiência no trabalho, que possibilita concretizar os princípios supramencionados, mas é apenas uma medida entre outras que podem ser adotadas. Inegavelmente, o papel do trabalho na vida das pessoas com deficiência tem a sua

Laborare. Ano IV, Número 6, Jan-Jun/2021, pp. 226-245. ISSN 2595-847X. https://revistalaborare.org/ DOl: https://doi.org/10.33637/2595-847x.2021-79 
potencialidade em elementos profundos, nos aspectos de autonomia, pessoais, emocionais e econômicos.

Por fim, é necessário estabelecer amplas oportunidades de acesso ao mercado de trabalho, com flexibilização no processo de recrutamento para garantir iguais oportunidades na contratação. Também, os empregadores, líderes e gestores precisam compreender a necessidade e importância de ter um profissional com deficiência em seu estabelecimento, aperfeiçoando a qualidade da empregabilidade, seja pela ampliação de quantidade e qualidade de vagas oferecidas ou incentivos no crescimento profissional, devendo ocorrer a efetiva inclusão à luz das normas internacionais e nacionais a fim de se garantir a dignidade da pessoa humana.

\section{REFERÊNCIAS BIBLIOGRÁFICAS}

BECKER, Kalinca Léia. Deficiência, Emprego e Salário no Mercado de Trabalho Brasileiro. Estudos Econômicos, São Paulo, v. 49, n. 1, p. 39-64, 2019. ISSN: 10.1590. DOI: https://doi.org/10.1590/0101-41614912klb. Disponível em: http://www.revistas.usp.br/ee/article/view/140395.

DE LUCA, Guilherme Domingos; RENZETTI FILHO, Rogério Nascimento. Direitos fundamentais da pessoa com deficiência: o trabalho como fonte da promoção da dignidade humana., Revista de Direito do Trabalho, São Paulo, SP, vol. 44, n. 185, p. 213-233, jan. 2018.

DELGADO, Maurício Godinho. Curso de Direito do Trabalho. 16. ed. São Paulo: LTR, $2017 b$.

\section{Princípios Constitucionais do Trabalho e Princípios de Direito} Individual e Coletivo do Trabalho. São Paulo: LTr, 2017a.

DELGADO, Maurício Godinho; DELGADO, Gabriela Neves. A reforma trabalhista no Brasil: com os comentários à Lei n. 13.467/2017. São Paulo: LTr, 2017.

DIEESE. Inclusão da pessoa com deficiência no mercado de trabalho. Nota Técnica 246 de 20 de novembro de 2020. São Paulo. Disponível em: https://www.dieese.org.br/notatecnica/2020/notaTec246InclusaoDeficiencia.html

Acesso em: 11 nov. 2020.

FÁVERO, Eugênia Augusta Gonzaga. Direitos da pessoa com deficiência: garantia de igualdade na diversidade. Rio de Janeiro: Editora WVA, 2004.

I.SOCIAL. Profissionais de Recursos Humanos: expectativas e percepções sobre a inclusão das pessoas com deficiência no mercado de trabalho, 2015. Disponível

Laborare. Ano IV, Número 6, Jan-Jun/2021, pp. 226-245. ISSN 2595-847X. https://revistalaborare.org/ DOI: https://doi.org/10.33637/2595-847x.2021-79 
em: https://www.abrhbrasil.org.br/cms/wp-content/uploads/2015/02/Pesquisa-iSocial2015.pdf. Acesso em: 18 jan. 2021.

IBGE. Censo Demográfico 2010 - características gerais da população, religião e pessoas com deficiência. Ministério do Planejamento, Orçamento e Gestão, Instituto Brasileiro de Geografia e Estatística - IBGE. ISSN 0104-3145, Rio de Janeiro. p.1215, 2010.

LEMOS, Rafael Diogo Diógenes. Cotas trabalhistas para pessoas com deficiência: uma análise principiológica. Revista de direito do trabalho, São Paulo, SP, v. 41, n. 164, p. 65-84, jul./ago. 2015.

MACIEL, Álvaro dos Santos. A inclusão da pessoa com deficiência no mercado de trabalho. Uma análise sob um enfoque histórico, filosófico e sociológico. São Paulo: LTr, 2011.

MARQUES, Rafael da Silva. Trabalho e dignidade humana. In: ALVARENGA, Rúbia Zanotelli [Org]. Direitos humanos dos trabalhadores. São Paulo: LTr, 2016, p. 171-182.

Ministério do Trabalho e Emprego (2011). Relação Anual de Informações Sociais. Brasília, 2011. Disponível em: http://pdet.mte.gov.br/rais/rais-2011. Acesso em 18 jan. 2021.

(2018). Relação Anual de Informações Sociais. Brasília, 2018. Disponível em: http://pdet.mte.gov.br/rais/rais-2018. Acesso em 18 jan. 2021.

ORGANIZAÇÃO INTERNACIONAL DO TRABALHO. Ninguém ficará pra trás, nem agora, nem nunca. Pessoas com deficiência na resposta ao COVID-19. 2020. Disponível em: $\quad$ https://www.ilo.org/wcmsp5/groups/public/---ed_emp/---ifp_skills/documents/ publication/wcms_741590.pdf. Acesso em: 11 dez. 2020.

RODRIGUEZ, Américo Plá. Princípios do Direito do Trabalho. Tradução por Wagner D. Giglio, 3.ed. São Paulo: LTR, 2000.

SANTOS, Ronaldo Lima dos. Sindicatos e ações coletivas: acesso à justiça, jurisdição coletiva e tutela dos interesses difusos, coletivos e individuais homogêneos. São Paulo: LTr, 2019. 5a Ed.

SELUR SOCIAL. Estatísticas do site. Sindicato das empresas de limpeza urbana no Estado de São Paulo. 2020. Disponível em: https://selur.org.br/wp-content/uploads/2020/12/Estat\%C3\%ADsticas-Selur-Social11.12.20-1.pdf. Acesso em: 22 jan. 2020.

SUPREMO TRIBUNAL FEDERAL (2016b). Ação Direta de Inconstitucionalidade número 5.357. Relator Ministro Edson Fachin. Diário de Justiça Eletrônico, Brasília,

Laborare. Ano IV, Número 6, Jan-Jun/2021, pp. 226-245. ISSN 2595-847X. https://revistalaborare.org/ DOl: https://doi.org/10.33637/2595-847x.2021-79 
DF, 17 de junho de 2016. Disponível em: http://portal.stf.jus.br/processos/detalhe.asp? incidente $=4818214$. Acesso em: 18 jan. 2021.

(2019). Ação Direta de Inconstitucionalidade número 5.760. Relator Ministro Alexandre de Moraes. Diário de Justiça Eletrônico, Brasília, DF, 20 de setembro de 2019. Disponível em: http://portal.stf.jus.br/processos/detalhe.asp? incidente $=5247635$. Acesso em: 18 jan. 2021.

TRIBUnAl SUPERIOR DO TRABAlHO (2016a). Ação Civil Pública. Processo número E-ED-RR-658200-89.2009.5.09.0670, Subseção I Especializada em Dissídios Individuais. Relator Ministro João Batista Brito Pereira. Diário de Justiça Eletrônico, Brasília, DF, 20 de maio de 2016. Disponível em: https://tst.jusbrasil.com.br/jurisprudencia/865715676/embargos-declaratoriosrecurso-de-revista-e-ed-rr-6582008920095090670. Acesso em 14 de jan. 2021.

(2017). Ação Anulatória. Processo número RO-76-64.2016.5.10.0000. Relatora Maria Cristina Irigoyen Peduzzi. Diário de Justiça Eletrônico, Brasília, DF, 11 de abril de 2017.2 Disponível em: http://aplicacao4.tst.jus.br/consultaProcessual/consultaTstNumUnica.do? consulta $=$ Consultar\&conscsjt $=\&$ numeroTst $=000076 \&$ digito $T$ st $=64 \&$ anoTst $=2016 \&$ orga oTst $=5 \&$ tribunalTst $=10 \&$ varaTst $=0000 \&$ submit $=$ Consultar\#. Acesso em: 18 jan. 2021 .

(2020). Ação Anulatória. Processo número 1000639-49.2018.5.00.0000. Relatora Ministra Kátia Magalhães Arruda. Diário de Justiça Eletrônico, Brasília, DF, 1 de dezembro de 2020. Disponível em: https://pje.tst.jus.br/consultaprocessual/detalhe-processo/1000639-49.2018.5.00.0000. Acesso em: 02 de dez. 2020.

UNITED NATION. Disability and Development Report. New York. 2019. Disponível em: $\quad$ https://www.un.org/development/desa/disabilities/wp-content/uploads/sites/ 15/2019/07/disability-report-chapter2.pdf. Acesso em: 09 jan. 2021.

WORLD HEALTH ORGANIZATION. World report on disability. Geneva, 2011. Disponível em: <https://www.who.int/disabilities/world_report/2011/report.pdf>. Acesso em: 12 jan. 2021.

Recebido: $14 / 12 / 2020$

Revisado: 30/01/2021

Aprovado: 31/01/2021

Laborare. Ano IV, Número 6, Jan-Jun/2021, pp. 226-245. ISSN 2595-847X. https://revistalaborare.org/ DOI: https://doi.org/10.33637/2595-847x.2021-79 